\title{
FORMAÇÃO IAPÓ: GLACIAÇÃO CONTINENTAL NO LIMITE ORDOVICIANO/SILURIANO DA BACIA DO PARANÁ
}

\author{
MÁRIO LUÍS ASSINE*, CARLOS J. S. ALVARENGA** \& JOSÉ ALEXANDRE J. PERINOTTO"
}

\begin{abstract}
IAPÓ FORMATION: CONTINENTAL GLACIATION IN THE ORDOVICIAN/SILURIAN BOUNDARY OF THE PARANA BASIN. The lapó Formation is a thin and widespread unit, generally less than 20 $\mathrm{m}$ thick and covering discontinuously an área of hundreds of thousand square kilometers. The main fácies is massivê diamictites, which display pebbles and cobbles in a mud matrix, some of them faceted and striated. The massive diamictites are considered subglacial tillites. The fácies association includes stratified diamictites, conglomerates, massive and stratified sandstones, and fine laminated fácies with dropstones. The glaciation in the Ordovician/Silurian boundary is well constrained and its correlation with other Gondwanan basins suggests maximum glacial in the Iate Ashgillian age. The lapó Formation is overlain by early Llandovery post-glacial transgressive shales of the Vila Maria Formation. It is herein proposed a modcl of glaciomarine stratigraphic architecture in a glaciated continental margin to explain the origin of the lapó Formation.
\end{abstract}

Keywords: lapó Formation, Ordovician-Silurian Glaciation, Paraná Basin,

RESUMO A Formação lapó é uma unidade delgada e de ampla distribuição geográfica na Bacia do Paraná. Apresenta-se geralmente com menos de $20 \mathrm{~m}$ de espessura, ocorrendo descontinuamente numa área de várias centenas de milhares de quilómetros quadrados. Diamictitos maciços constituem a principal fácies, ocorrendo seixos facetados e estriados, sendo considerados tilitos subglaciais. A associação de fácies inclui também diamictitos estratificados, conglomerados, arenitos maciços e fácies pelíticas com seixos caídos. A Formação lapó é produto de glaciação no limite Ordoviciano/Siluriano e sua correlação com unidades de outras bacias gondwânicas sugere máximo glacial no Áshgilliano terminal. A Formação lapó é recoberta por folhelhos marinhos eollandovcrianos da Formação Vila Maria. É proposto modelo de glaciação continental, com geleiras avançando sobre sistemas marinhos rasos, para explicar a origem da Formação lapo.

Palavras-chaves: Formação lapó, Glaciação Ordoviciana-Siluriana, Bacia do Paraná

INTRODUÇÃO A Formação lapó ocorre sotoposta aos arenitos conglomeráticos e conglomerados da base da Formação Furnas. Foi descrita e formalizada no Estado do Paraná por Maack (1947), que a considerou de origem glacial e de idade siluriana. Na seção-tipo, situada na Serra de São Joaquim a oeste da cidade de Castro, Maack (1947) caracterizou duas fácies distintas: diamictitos avermelhados e de matriz arenosa, sobrepostos por diamictitos de coloração cinza azulada e matriz síltico-arenosa (Fig. 1).

Desde a caracterização da unidade até o final dos anos 80 , poucos trabalhos enfocaram a estratigrafia da Formação lapó. Dúvidas sobre sua natureza, origem e idade persistiram durante anos, fato que se depreende do relato de Rocha-Campos (1981). A pequena espessura e ausência de exposições di ficultou sobremaneira seu estudo. Neste aspecto, destaca-se o trabalho de mapeamento realizado por Vieira \& Mainguc (1972), onde foram cartografadas ocorrências da unidade no Estado do Paraná.

Considerando a presença da unidade em vários poços no interior do Estado do Paraná, Assine \& Soares (1989) demonstraram a correlação dos diamictitos da Formação lapó com diamictitos existentes na faixa de afloramentos de Goiás, originalmente incluídos na base da Formação Vila Maria (Faria 1982). Tal correspondência fora inicialmente sugerida por Caputo \& Crowell (1985).

Posteriormente, Assine et al (1994) propuseram que os diamictitos e fácies associadas, que formam um horizonte estratigráfíco único, fossem classificados como Formação lapó (Fig. 2). Esta proposição resgatou e deu importância à definição original de Maack (1947), restringindo a denominação Formação Vila Maria aos pelitos e arenitos marinhos silurianos sobrepostos.

O objetivo deste trabalho é apresentar uma síntese do conhecimento atual sobre a Formação lapó. Novos dados de superfície e subsuperfície (Assine 1996) foram incorporados, delineando uma distribuição geográfica mais ampla do que vinha sendo considerado. As fácies sedimentares foram descritas utilizando-se o código de fácies proposto por Eyles et ai (1983), visando estabelecer o empilhamento estratigráfico vertical e os paleoambientes sedimentares. A idade dos diamictitos é discutida, buscando-se estabelecer correlações com outras bacias gondwânicas. Por fim, é apresentada uma tentativa de reconstrução paleogeográfica baseada no modelo de glaciação de plataforma.

DISTRIBUIÇÃO GEOGRÁFICA Segundo Maack (1950-51), no Estado do Paraná a Formação lapó ocorre da Serra de São Joaquim até o norte de Piraí do Sul. Afloramentos da unidade são, contudo, difíceis de serem encontrados no campo porque a unidade é pouco espessa, de natureza descontínua e frequentemente coberta por depósitos de talus. Na estrada de Piraí para Ventania, Vieira (1973) descreveu um afloramento bastante representativo, onde a Formação lapó assenta em discordância angular sobre rochas sedimentares ordovicianas do Grupo Castro (Fig. 3A). Para sul, a unidade foi encontrada no canyon do rio São Jorge (Borghi \& Schubert 1995), em Ponta Grossa (Fig. 3B).

Para norte, a faixa aflorante da unidade pode ser estendida do Paraná até o sul do Estado de São Paulo, pois na estrada que liga Bonsucesso a Itapeva, sotopostos à Formação Furnas, ocorrem diamictitos cinza arroxeados sustentados por matriz síltico-argilosa e constituídos por seixos de diversas composições, muito semelhantes aos descritos no Paraná. Diamictitos nesta região, sotopostos à Formação Furnas, foram pela primeira vez relatados por Petri \& Fulfaro (1967), embora considerados de idade pré-cambriana por esses autores.

No flanco norte da bacia, no sul do Estado de Goiás, a unidade aflora numa faixa contínua de oeste de Iporá até Bom Jardim de Goiás, onde a Formação lapó assenta diretamente sobre o embasamento pré-cambriano(Fig. 4). A seção do

* Unesp/IGCE/Departamento de Geologia Sedimentar, Av. 24-A/1515, CP 178, CEP 13506-900, Rio Claro-SP, Brasil, e-mail: assine@caviar.igce.unesp.br

** UnB/IG/Departamento de Geologia Geral e Aplicada, Campus Universitário, CP 4465, CEP 70910-900, Brasília-DF, Brasil,

e-mail: alval@guarany.cpd.unb.br 


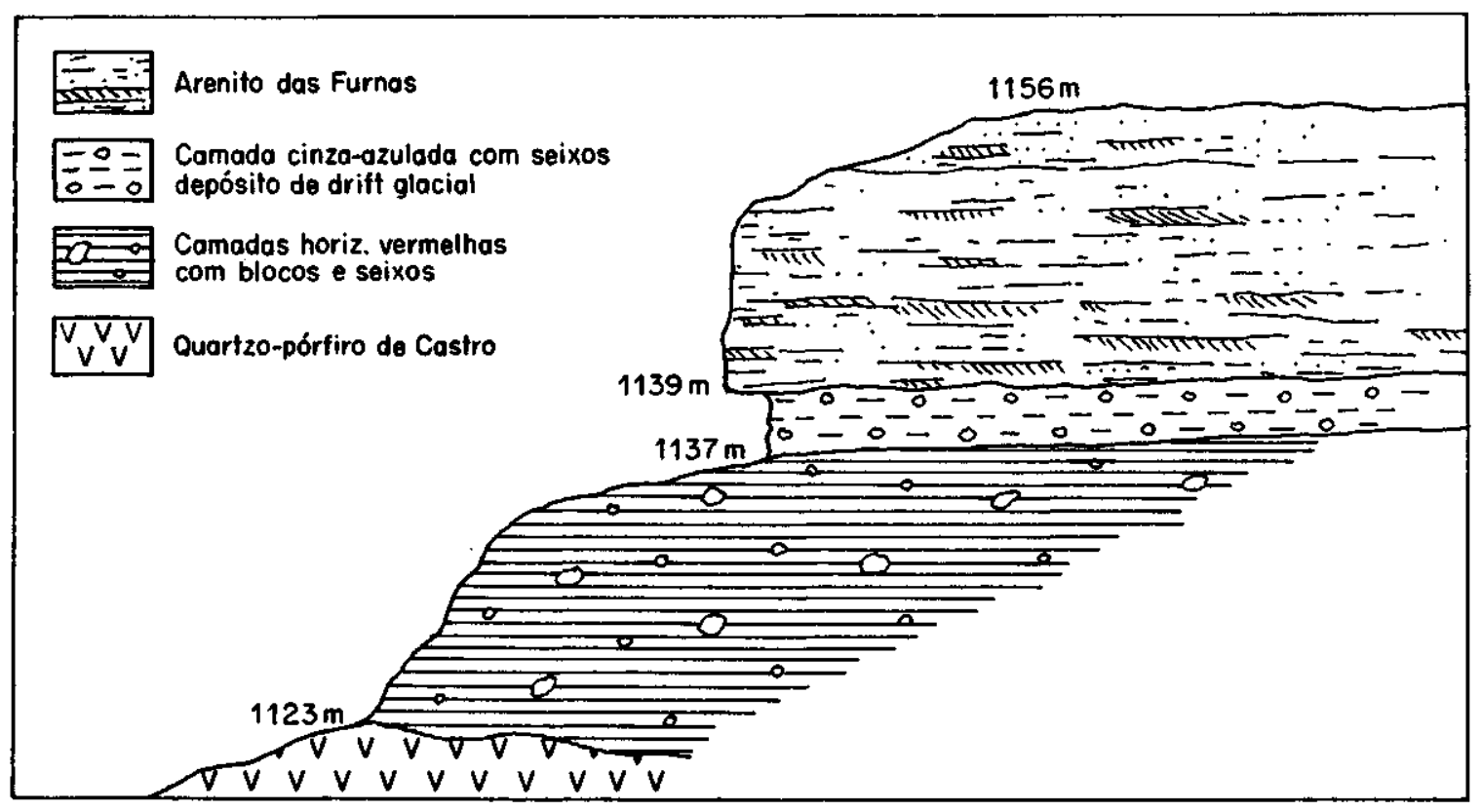

Figura 1 - Seção-tipo da Formação lapó, conforme definida por Maack em 1947 (Serra de São Joaquim; km 16 da rodovia Castro-Tibagi).

Figure 1 - Type-section of the lapó Formation, according to Maack (1947)

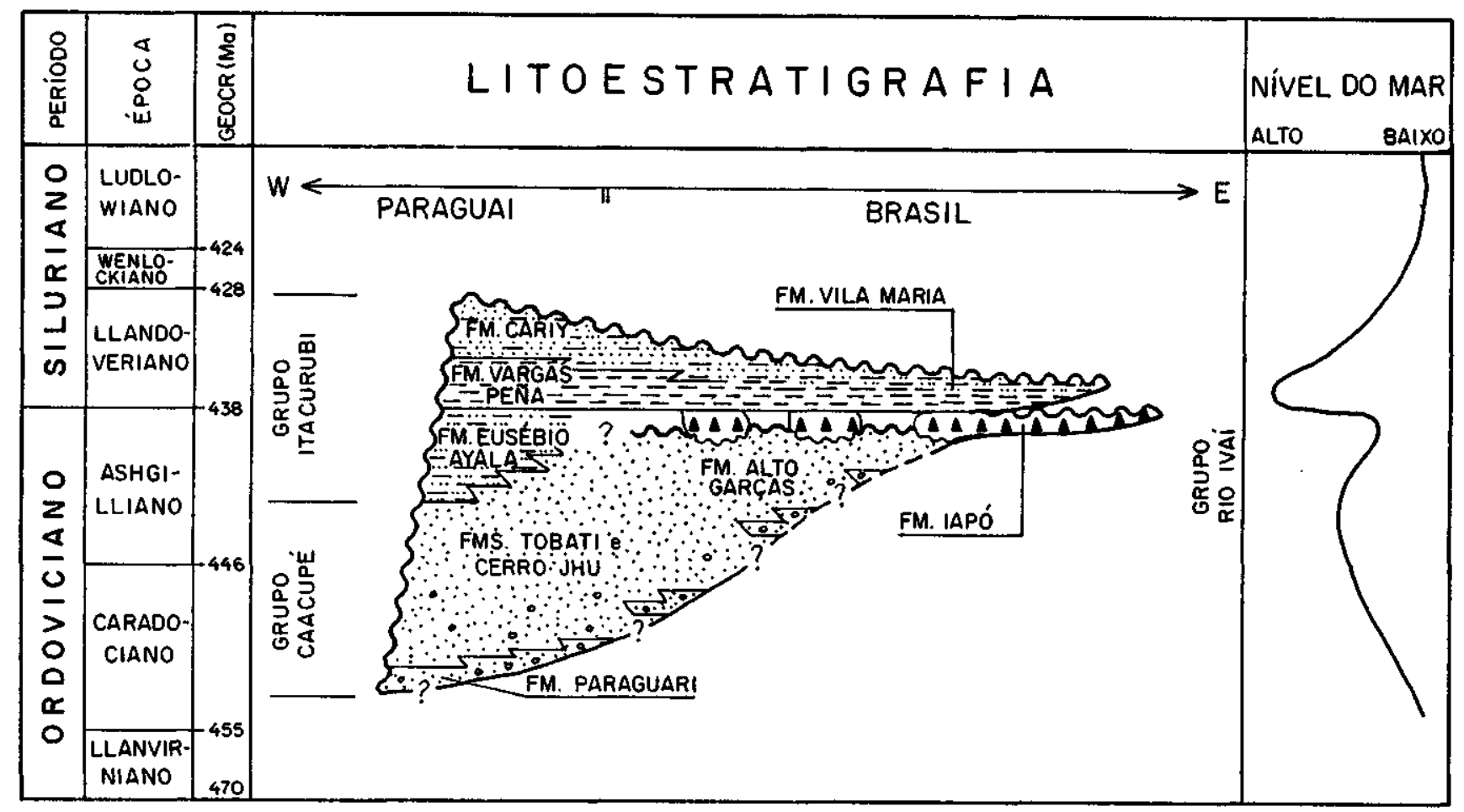

Figura 2 - Carta cronoestratigráfica da sequência ordovício-silltriana da Bacia do Paraná (modif. de Assine et al. 1994) Figure 2 - Chronostratigraphic chart for the Ordovician-Silurian sequence of the Paraná basin (modif. from Assine et al. 1994)

córrego da Aldeia, situada a sudeste de Bom Jardim de Goiás, foi escolhida como seção-tipo da Formação Vila Maria, conforme inicialmente definida por Faria (1982). A Formação lapó ocorre também mais a oeste, nos municípios de Baliza (GO) e de Barra do Garças (MT), nestas áreas sobrepondo uma delgada seção de arenitos médios a grossos, considerados as ocorrências mais proximais da Formação Alto Garças.

Registra-se que Beurlen (1959) já havia notado a existência de uma seção elástica sotoposta à Formação Furnas ao longo do rio das Garças, entre Barra do Garças e General Carneiro. Caracterizou-a (Beurlen 1959, p. 38) como "uma sequência basal de pequena espessura, constituída de siltitos vermelhos, bem estratificados, às vezes argilosos, localmente, até mesmo arguas sílticas e siltitos de aspecto tilítico. Em nenhum lugar se podem observar os contatos estratigráficos dessa estranha sequência. Mas ela ocorre sempre na Serra, em baixo e sob os arenitos grosseiros, conglomeráticos". $\mathrm{Na}$ extremidade sudeste da Serra do Taquaral (noroeste de Barra do Garças), 
(A)

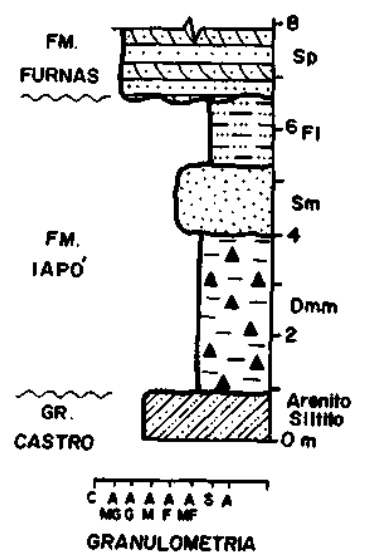

$\begin{array}{ll}\text { Dmm } & \text { Diamictto maciço } \\ \mathrm{FI} & \text { Flnot laminados } \\ \mathrm{Sm} & \text { Arenito maciço } \\ \mathrm{Sp} & \text { Arenito com estratificação cruzada planar }\end{array}$

Figura 3- Perfis estratigráficos verticais da Formação lapó no Estado do Paraná: A) estrada Pirai do Sul-Ventania; B) rio São Jorge, Ponta Grossa

Figure 3 - Vertical stratigraphic profiles of lhe lapó Formation in the Paraná State: A) Piraí do Sul-Ventania highway; B) São Jorge river, Ponta Grossa

na colónia Voadeira, situada no córrego homónimo, Beurlen (1959, p. 32) assim descreveu a seção sotoposta aos arenitos conglomeráticos brancos da base da Formação Furnas: "O vale do córrego apresenta, nos arredores da colónia, na lapa, um arenito vermelho bem estratificado, com bancos da espessura de 20 a 40 centímetros, sem estratificação cruzada. A granulação é média ou fina, bastante monótona. Além dos grãos de quartzo, ocorre muita moscovita. O limite inferior deste arenito não pode ser observado, razão porque a espessura total é desconhecida. Segue-lhe na capa um metro de arenito conglomerático, com pequenos seixos: este é encimado por um siltito argiloso, não estratificado, com seixos esparsos, pequenos, apresentando, assim, aspecto semelhante ao de um tilito um pouco arenoso. A espessura desse siltito 'tilítico' é, aproximadamente, de 5 metros, realçando-lhe a cor rosada. E capeado de um arenito fino, bem estratificado, rico em moscovita". Embora tenha interpretado esta seção como parte da sequência devoniana, considerou que "à primeira vista parece plausível que as ditas ocorrências representem um equivalente da formação glacial lapó, descrita por Maack, na lapa do arenito Furnas, no Paraná" (Beurlen 1959, p. 42).

Pouco se conhece sobre a Formação lapó no flanco noroeste da bacia e as informações disponíveis carecem ainda de detalhamento. Na região de Rio Verde de Mato Grosso, diamictitos (fácies Dmm) e folhelhos com seixos caídos (fácies Fld), capeando os arenitos da Formação Alto Garças, foram considerados pertencentes à Formação lapó. Na região da chapada dos Guimarães, Borghi \& Moreira (1996) relataram a ocorrência de diamictitos da Formação lapó recobrindo arenitos da Formação Alto Garças.

Na figura 5 estão indicados os pontos onde a Formação lapó foi constatada, com as respectivas espessuras medidas, assim como o limite inferido de ocorrência em subsuperficie.

Do exposto acima verifica-se que a unidade tem ocorrência geográfica ampla, ao mesmo tempo que sua espessura é pequena, normalmente menor que $20 \mathrm{~m}$. Uma espessura anómala foi verificada apenas no poço 2-JT-1-PR (Joaquim
Távora), que atravessou $73 \mathrm{~m}$ de diamictitos sem ter atingido a base da unidade.

ORIGEM GLACIAL Da análise das figuras 3 e 4 verifica-se que o empilhamento estratigráfico é caracterizado por um conjunto de fácies (Fig. 6) que se apresenta numa sequência vertical repetitiva na maior parte das seções descritas. Na base ocorrem diamictitos maciços (fácies Dmm) e conglomerados (fácies $\mathrm{Gm}$ ) justapostos lateralmente. Arenitos grossos a conglomeráticos, maciços (fácies $\mathrm{Sm}$ ) ou com estratificações cruzadas planar (fácies $\mathrm{Sp}$ ) e acanalada (fácies $\mathrm{St}$ ), apresentam-se aleatoriamente sob a forma de canais irregulares, truncando por erosão as fácies subjacentes. Em algumas seções verificou-se a presença de formas canalizadas na base da Formação lapó, preenchidas por diamictitos e conglomerados. Para o topo, comparecem diamictitos fracamente estratificados (fácies Dms) e/ou arenitos com ondulações de corrente (fácies Sr). Quando a seção é completa, a sucessão vertical culmina com a presença de lamitos com seixos pingados (fácies Fld), alguns com evidências de ritmicidade (Fig. 7).

Deposição subaquosa foi interpretada para as fácies Dms, $\mathrm{Sr}$ e Fld. A presença de seixos caídos (fácies Fld) caracteriza a presença de material transportado por gelo flutuante (icerafts), indicando que se tratam de sedimentitos glaciogênicos ou glacialmente influenciados. Deposição marinha é comprovada pela presença de macrofósseis (orbiculoideas e archeogastrópodes), observados na seção do Conjunto Residencial Araguaia em Barra do Garças (Fig. 7).

Os diamictitos maciços (fácies Dmm) são cinza arroxeados a marrom avermelhados, apresentam matriz síltico-arenosa e base erosiva, sendo texturalmente heterogéneos (grânulos a matacões), litologicamente polimíticos. Os clastos apresentam evidências de abrasão glacial, sendo subangulosos a subarredondados, facetados, muitos corn forma de bala (bullet-shaped clasts) e alguns estriados. Segundo Maack (195051, p. 204), os clastos constituem uma mistura heterogénea de material estranho ao país e rochas das vizinhanças.

Por estas características faciológicas, pela pequena espessura e ocorrência descontínua, por assentarem-se diretamente sobre o embasamento e serem sobrepostos por fácies subaquosas glacialmente influenciadas, são interpretados como depósitos subglaciais, como já o fizeram anteriormente Pereira (1992) e Assine \& Soares (1993).

Ambientes subglaciais são pela sua própria natureza extremamente complexos, havendo diversidade muito grande de processos e fácies sedimentares. A íntima associação dos diamictitos maciços (fácies Dmm) com conglomerados (fácies $\mathrm{Gm}$ ), arenitos maciços (fácies $\mathrm{Sm}$ ) e arenitos com estruturas trativas indicativas de fluxo em meio aquoso (fácies $\mathrm{Sp})$ sugere geleiras de base úmida.

A existência de afloramentos isolados e a não constatação da unidade em muitos poços não se devem apenas a problemas de exposição, de erosão ou de identificação, mas também ao caráter descontínuo dos diamictitos. As fácies subglaciais são por natureza de pequena espessura e apresentam descontinuidade geográfica, pois formam elevações isoladas paralelas ao movimento das geleiras. Além disso, a descontinuidade das ocorrências pode ser consequência de irregularidades na superficie do substrato sobre o qual se depositaram, como aventaram Borghi \& Schubert (1995). Por isto, interpretações tectônicas baseadas unicamente na existência ou não de diamictitos da Formação lapó, como as apresentadas por Faria et al. (1994), devem ser vistas com cautela.

IDADE Os diamictitos da Formação lapó são sobrepostos pêlos folhelhos transgressivos da Formação Vila Maria, cuja idade eollandoveriana foi determinada por Gray et al. (1985) a partir do estudo de esporos de plantas terrestres, acritarcas e prasinófitas. Este fato indica que a Formação lapó não é 

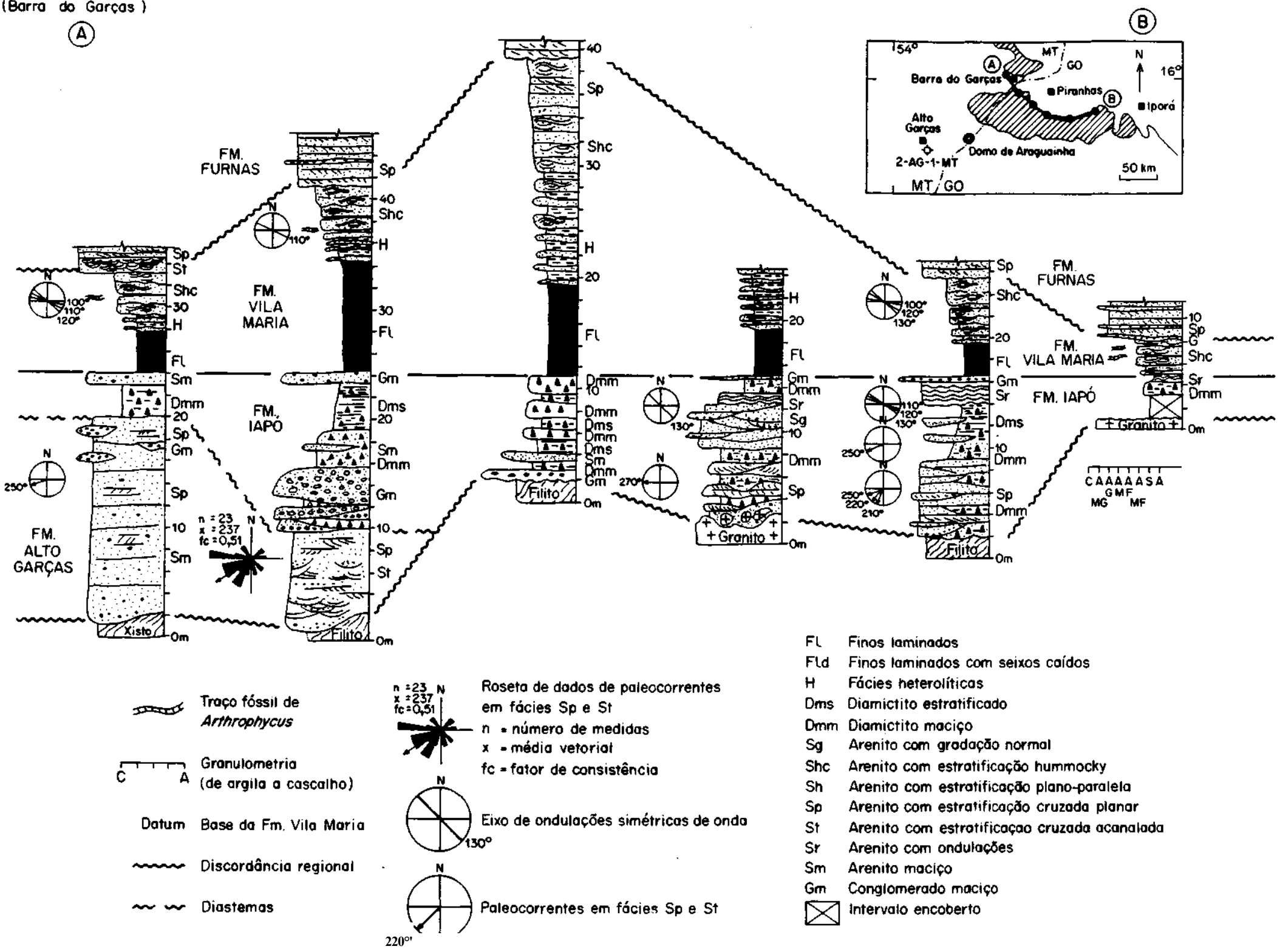


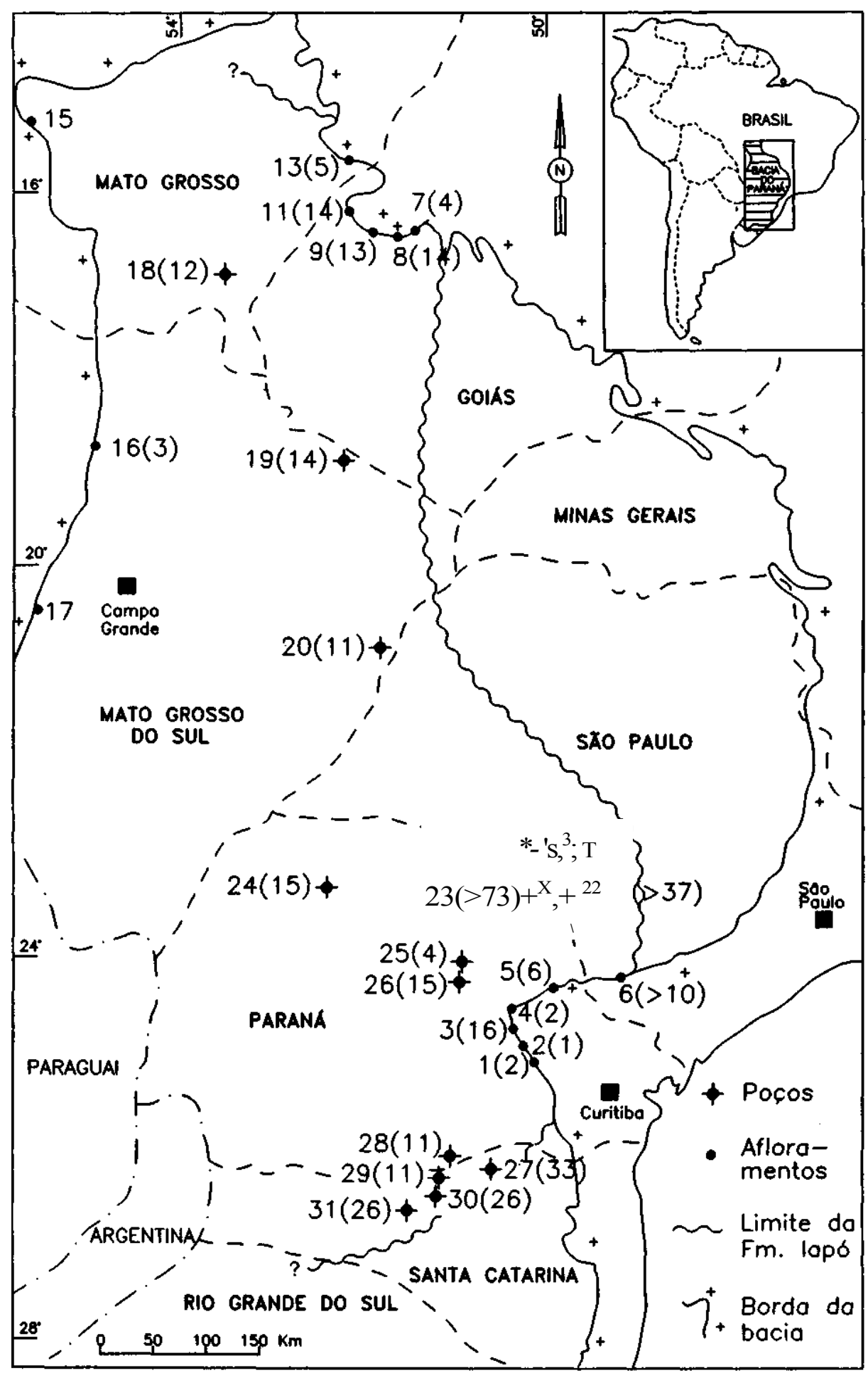

Figura 5 - Ocorrências da Formação lapó em afloramentos e poços (1= canyon do rio São Jorge, Ponta Grossa-PR; $2=$ estrada para Catanduvas, Carambei-PR; $3=$ seção-tipo na rodovia Castro-Tibagi, km!6; $4=$ canyon do rio lapó, Castro-PR; $5=$ estrada Piraído SuUVentania-PR; 6= estrada Itapeva/Bonsucesso-SP; 7= córrego Buriti Feio, sul de Iporá-GO; 8=Vila Maria-GO; 9= $25 \mathrm{~km}$ a sul de Piranhas; 10= córrego da Aldeia, sudeste de Bom Jardim de Goiás-GO; 11= cachoeira no ribeirão das Perdizes, sudeste de Baliza-GO; 12= estrada para a Fazenda Colorado, sudeste de Baliza-GO; 13= Conjunto Residencial Araguaia, Barra do Garças-MT; 14= estrada do rio Peixinho para a base do CINDACTA, Barra do Garças-MT; 15= redondezas da caverna Aroe Jari, leste de Chapada dos Guimarães-MT; 16= estrada para o Pantanal, noroeste de Rio Verde de Mato Grosso-MS, acesso a partir do km 682 da BR-163; 17=fazenda Concremixem Cipolândia, norte de Aquidauana-MS; 18=2-AG-1-MT; 19= 2-RA-1-MS; $20=2-T L-1-M S ; 21=1-M A-1-S P ; 22=1-S A-1-S P ; 23=1-J T-1-P R ; 24=2-R I-1-P R ; 25=1-M O-2-P R ; 26=2-M O-1-P R ; 27=$ $2-C N-1-S C ; 28=2-U V-1-S C ; 29=2-P U-1-S C ; 30=1-M C-2-S C ; 31=1-T P-3-S C)$ e suas respectivas espessuras em metros (números entre parênteses)

Figure 5 - lapó Formation in outcrops and wells (numbers refers to different occurrences) and its thicknesses in meters (numbers in parenthesis) 

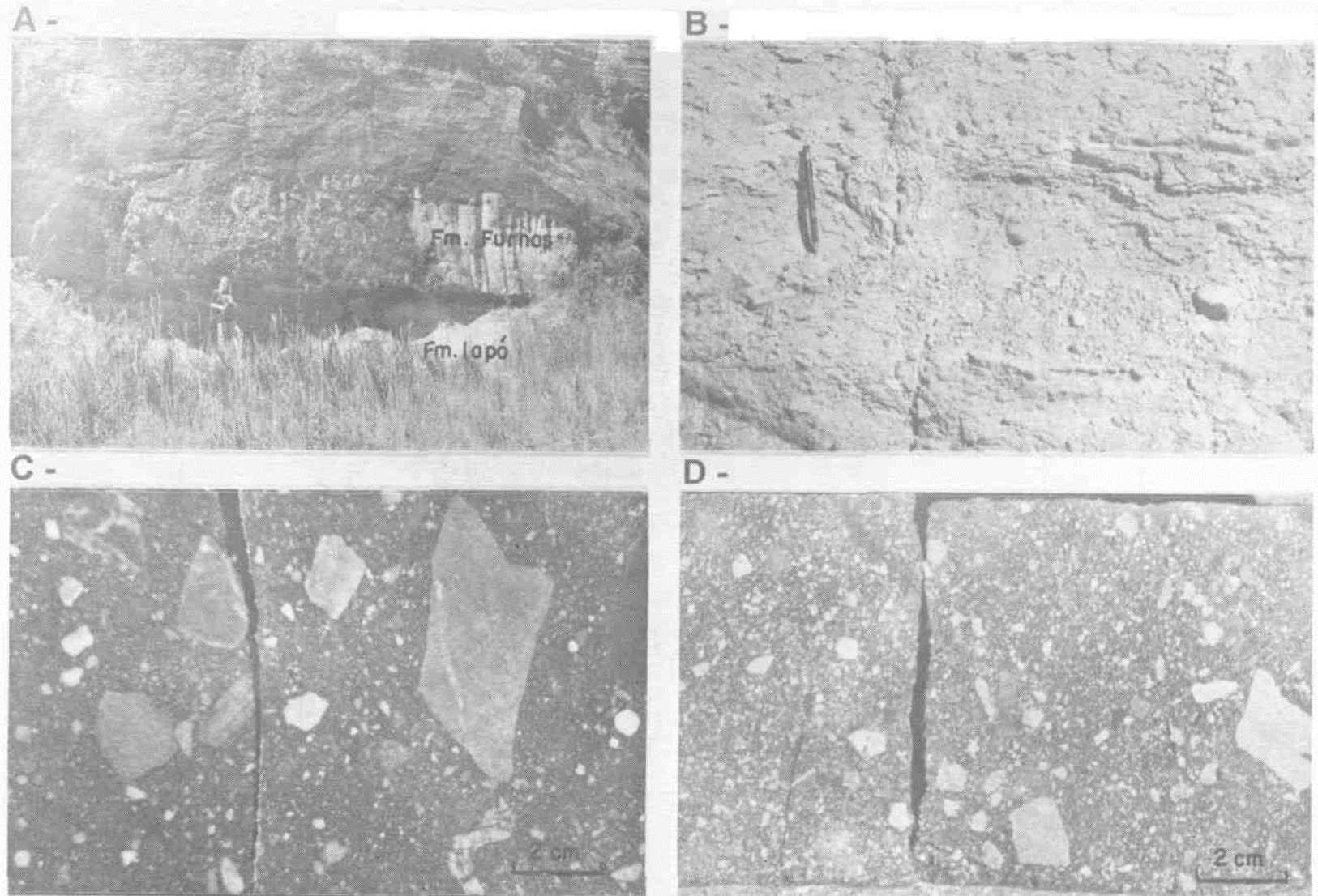

E -

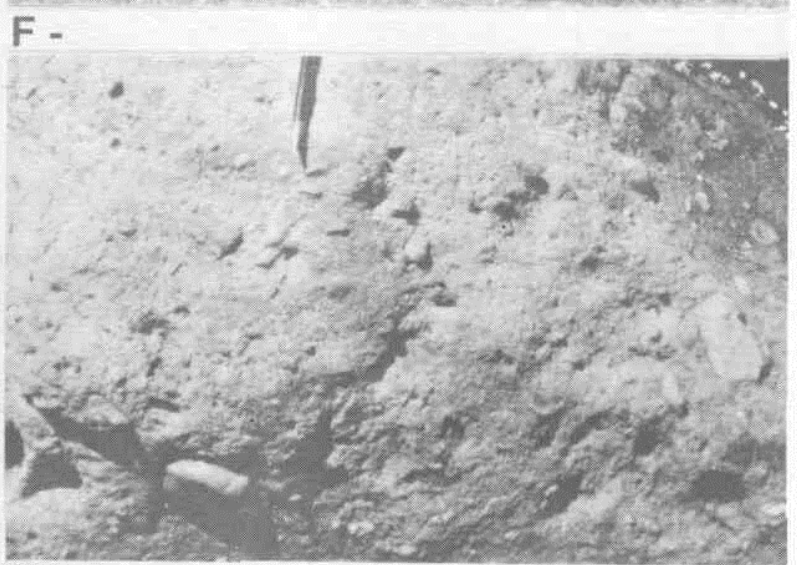

G -

$\mathrm{H}$
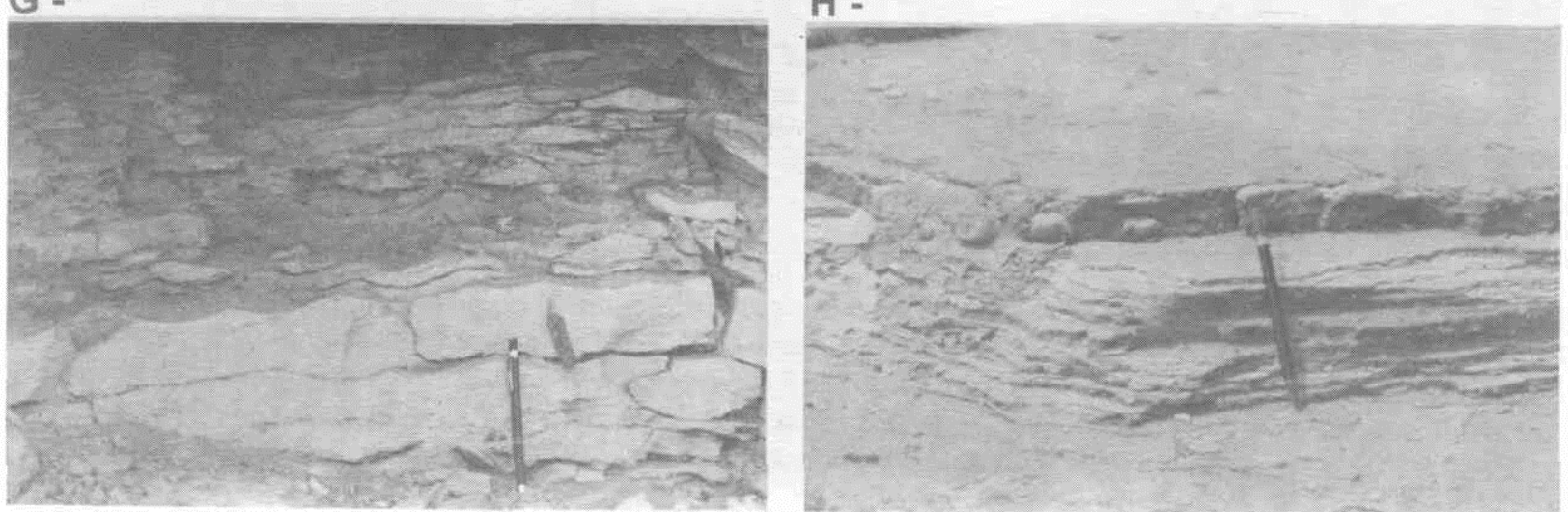

Figura 6-A) e B) Fácies Dmm - diamictitos maciços - na seção-tipo da Formação lapó; C) e D) Fácies Dmm nos poços 2-PU-1 -PR e 2-MO-1-PR; E) Mutações de granitos ocorrem localmente nos diamictitos; F) Fácies Gm-conglomerados maciços; G) Fácies Sr - arenitos com ondulações de corrente indicam retrabalhamento por correntes; H) Fácies Fld -pelitos laminados com seixos caídos

Figure 6-A) and B) Fácies Dmm - massive diamictites - in the type-section of the lapó Formation; C) and D) Fácies Dmm in the wells 2-PU-1 -PR and 2-MO-1 -PR; E) Granite boulders in the diamictites; F) Fácies Gm - massive conglomerates; G) Fácies Sr - Ripple sandstones; H) Fácies Fld - Fines with dropstones 


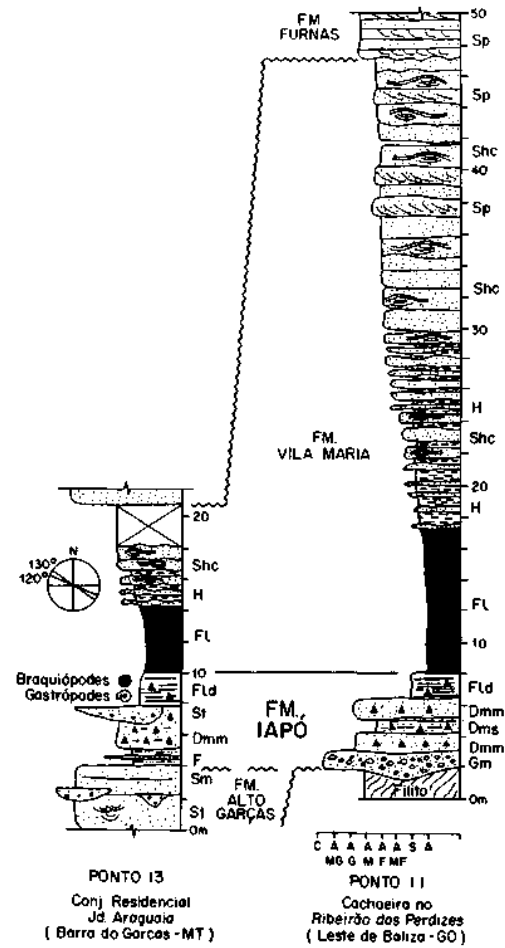

Figura 7 - Fácies Fld no topo da Formação lapó Figure 7 - Fácies Fld at the top of the lapó Formation

mais jovem que eollandoveriano. Além disso, a existência de depósitos conglomeráticos (fácies $\mathrm{Gm}$ ) residuais (lags), possivelmente transgressivos, entre os diamictitos subglaciais da Formação lapó e os folhelhos transgressivos da Formação Vila Maria, que podem ser observados nos perfis da figura 4, indica descontinuidade entre ambas as unidades. Por outro lado, os diamictitos são mais jovens que Ordoviciano Médio, já que sobrepõem em discordância angular rochas sedimentares e vulcânicas desta idade pertencentes ao Grupo Castro.

Sua idade precisa, entretanto, ainda está por ser estabelecida, pois as amostras coletadas se apresentaram estéreis em microfósseis. Macrofósseis (orbiculoideas), existentes na fácies Fld em afloramentos em Barra do Garças (Fig. 7), também não forneceram informações de valor cronoestratigráfico.

No Brasil, diamictitos depositados no interregno Ashgilliano/Llandoveriano ocorrem também nas formações Nhamundá da Bacia do Amazonas e Ipu da Bacia do Parnaíba. Estes diamictitos ainda não foram diretamente datados, mas são sobrepostos por folhelhos llandoverianos das formações Pitinga e Tianguá respectivamente (Grahn \& Caputo 1992).

Diamictitos posicionados abaixo de folhelhos llandoverianos foram descritos em várias bacias gondwânicas sul-americanas. Dada a falta de elementos que permitissem sua datação e considerando um contato concordante com os folhelhos llandoverianos, vários autores atribuíram uma idade eo-siluriana para estes diamictitos.

No noroeste da Argentina, diamiclitos eopaleozóicos constituem a Formação Zapla, cuja natureza glacial foi inicialmente estabelecida por Schlagintweit (1943), que a eles se referiu como "horizonte glacial de Zapla". Os diamictitos da Formação Zapla constituem um importante horizonte guia, reconhecível da Bacia Chaco-Paranense (Argentina) até o Peru (Laubacher et al. 1982). Na Bolívia são referidos como Formação Cancaniri, cuja idade tem sido matéria de divergências já que não há datações seguras. Muitos fósseis retraba-
Ihados (trilobitas, braquiópodos, moluscos e briozoários) dificultam sua datação (Suárez-Soruco 1992).

Informações cronoestratigráficas mais precisas foram obtidas nas serras subandinas de Salta e Jujuy. Nesta área a Formação Zapla jaz em discordância sobre estratos do Ordoviciano Médio, apresentando espessura máxima de $120 \mathrm{~m}$. E constituída por diamictitos na base e arenitos e siltitos na parte superior, onde Monaldi \& Boso (1987) encontraram restos de braquiópodos e trilobitas do género Dalmantina, o que permitiu o posicionamento da unidade no Ashgilliano.

$\mathrm{Na}$ Precordilheira Argentina foram encontrados trilobitas e braquiópodes ashgillianos em siltitos sobrepostos aos diamictitos da Formação Dom Bráulio (Levy \& Nullo 1974, Baldis \& B lasco 1975, Benedetto 1990, Sánchez et al. 1991). Os diamictitos apresentam clastos facetados e estriados, tendo sido inteipretados como o registro da glaciação neo-ordoviciana na Precordilheira Argentina (Peralta \& Cárter 1990).

Embora não dispondo de datações na maioria dos casos, Peralta \& Baldis (1992) correlacionaram várias ocorrências de diamictitos descritos em diferentes bacias da América do Sul, todos situados imediatamente abaixo de folhelhos eollandoverianos, sugerindo que os diamictitos são cronocorrelatos e produto de glaciação ao final do Ordoviciano.

Diamictitos posicionados abaixo de folhelhos llandoverianos foram descritos em várias outras bacias gondwânicas fora da América do Sul. Diamictitos da Formação Pakhuis, subjacentes aos folhelhos llandoverianos da Formação Cedarberg da Bacia do Cabo na África do Sul, são considerados de idade neo-ordoviciana (Visser 1992). Idades neo-ordovicianas foram atribuídas aos diamictitos do Grupo Tichit da Bacia de Taoudeni do norte da África (Deynoux 1985) e aos das formações Sarah e Zarqa do Oriente Médio (Vaslet 1990), situados na margem norte do continente de Gondwana, pois os folhelhos sobrepostos aos diamictitos apresentam formas hirnantianas (Neo-Ashgilliano). Diamictitos glaciais de idade ashgilliana também foram constatados nos terrenos gondwânicos da Península Ibérica, Normandia e República Tcheca (Brenchley et al. 1991).

A presença de diamictitos na mesma posição estratigráfica em bacias geograficamente tão distantes como as de Taoudeni (Mauritania), do Cabo (África do Sul) e da Precordilheira Argentina, testemunha a ocorrência de glaciação gondwânica continental no limite Ordoviciano/Siluriano, com máximo avanço da calota polar no Neo-Ashgilliano .

Com base nas considerações feitas, infere-se que os diamictitos da Formação lapó constituem o registro sedimentar, na Bacia do Paraná, da glaciação no interregno Ashgilliano/Llandoveriano, provavelmente com ápice no Neo-Ashgilliano (Hirnantiano).

GLACIAÇÃO CONTINENTAL A Formação lapó apresenta grande extensão em área, espessura pequena (no geral menor que $20 \mathrm{~m}$ ), empilhamento numa sequência lógica e previsível e a presença de clastos de variadas composições, inclusive de tipos litológicos não constatados no embasamento adjacente. Estas características, segundo critérios apresentados por Visser (1989), indicam glaciação continental (continental or shelf glaciation) em oposição à glaciação de altitude (mountain glaciation).

Esta interpretação é corroborada pela existência de depósitos cronocorrelatos na maioria das bacias gondwânicas, cujas datações têm indicado máximo glacial no Neo-Ordoviciano. Ao final do Ordoviciano, o pólo sul estava posicionado no centro-norte do atual continente africano e a calota polar avançou em direção às latitudes mais baixas, cobrindo as plataformas continentais que bordejavam a Gondwana (Fig. 8). A Bacia do Paraná encontrava-se entre $50^{\circ}$ e $60^{\circ}$ de latitude sul ao tempo da deposição da Formação lapó. 
As paleocorrentes, medidas em arenitos e conglomerados associados aos diamictitos da Formação lapó (Fig. 4), indicam fluxo para oeste-sudoeste em direção às bacias do Chaco, compatível com a movimentação da calota polar apresentada na reconstrução paleogeográfica da figura 8 .

Em seu movimento para oeste, as geleiras avançaram por sobre um mar epicontinental onde se depositavam areias (Formação Alto Garças). O advento da glaciação resultou em queda do nível do mar, evidenciada pela existência de fácies conglomeráticas intercaladas nos arenitos marinhos do topo da Formação Alto Garças no flanco oeste da bacia.

A seção psamítica da Formação Alto Garças se acunha para leste em direção à borda da bacia, constituindo as ocorrências de Baliza (Fig. 4) e Barra do Garças as mais proximais da unidade. Nestas áreas a unidade é pouco espessa, apresentando também intercalações de conglomerados em sua porção superior. Além dos conglomerados, ocorrem também arenitos maciços com clastos dispersos (fácies $\mathrm{Sm}$ ), às vezes com evidências de fluidização e deformação penecontemporânea, o que sugere sedimentação rápida por fluxos de natureza gravitacional. Tais fácies são interpretadas como depósitos de outwash, depositados por fluxos emanados de geleiras com sentido de deslocamento para oeste, o que é corroborado pelas paleocorrentes medidas nos arenitos da Formação Alto Garças (Fig. 4).

Frequentemente, diamictitos da Formação lapó sobrepõem os arenitos da Formação Alto Garças em contatos abruptos, indicativos de descontinuidade na sedimentação. Localmente
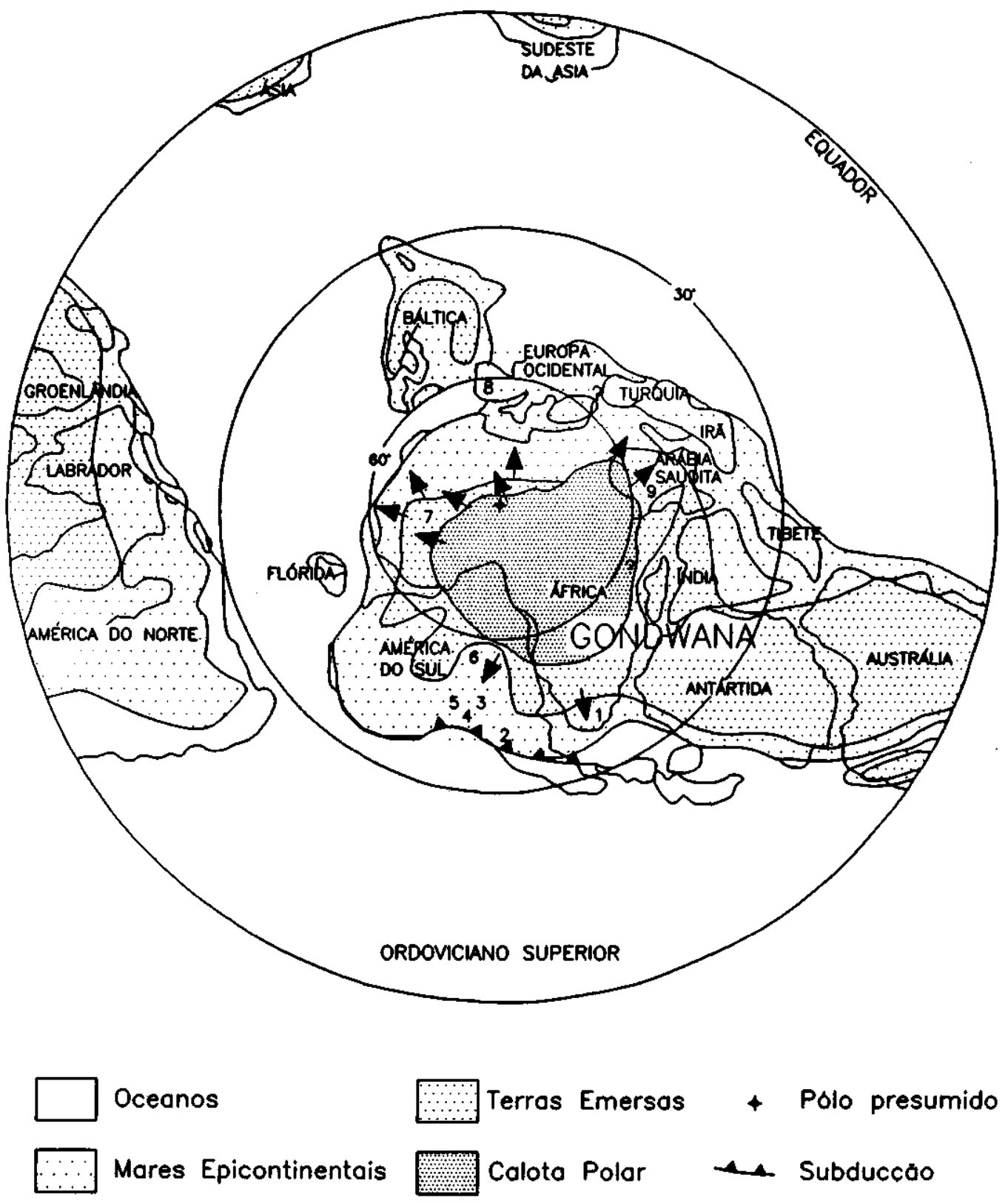

Oceanos

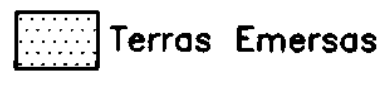

+ Polo presumido

Mares Epicontinentais
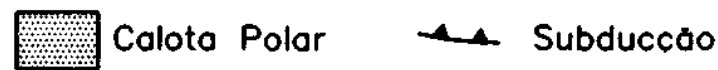

Direção de movimento das geleiras

Figura 8 - Reconstrução paleogeográfica (modif. de Vaslet 1990) da Gondwana no Neo-Ordoviciano (l- Bacia do Cabo; $2=$ Precordilheira Argentina; 3- Bacia do Chaco; 4- Zona siibandina na Bolivia; 5=Altiplano boliviano; 6= Bacia do Paraná; 7= Bacia de Taoudeni na Mauritania; 8= Portugal; $9=$ Arábia Saudita)

Figure 8 - Paleogeographic reconstruction (modif. from Vaslet 1990) of Gondwana in the Late Ordovician (1= Cape basin; $2=$ Argentine Precordillera; Chaco basin; 4=Bolivian subandean zone; 5= Bolivian Altiplane; 6=Paraná basin; 7=Taoudeni Basin in Mauritania; 8= Portugal; 9= Saudi Arabia) 
há evidências de erosão, seja por abrasão glacial ou pela ação de correntes de outwash ou de retrabalhamento por agentes marinhos. Nem sempre, porém, existe descontinuidade significativa, como na seção da fazenda Colorado (Fig. 4) na região de Baliza (GO) e nos testemunhos do poço 2-RI-1-PR (Rio Ivaí). Neste poço uma delgada intercalação de arenitos finos recorre nas fácies conglomeráticas da Formação lapó.

A sucessão de fácies e eventos geológicos descritos está mostrada na figura 9, adaptada do modelo evolutivo de deposição glacial em plataformas continentais proposto por Boulton (1990). Dentre vários aspectos interessantes advindos da aplicação do modelo, destacam-se:

1. Regressão em mares periglaciais, sujeitos ao avanço das geleiras, dá-se fundamentalmente no início do ciclo glacial. A este fato é atribuída a natureza regressiva dos arenitos marinhos plataformais/costeiros do topo da Formação Alto Garças;

2. Durante o máximo glacial, quando o nível global do mar cai, nos mares periglaciais sujeitos ao avanço de geleiras o nível relativo do mar sobe em consequência de subsidência por sobrecarga do gelo. Desta forma, dependendo de fatores como posição paleogeográfica (proximal ou distai) ou variações da espessura de gelo, as taxas de variação relativa do nível do mar são diferentes, de sorte que erosão em alguns locais ocorre simultaneamente à deposição contínua em outros. O contato da Formação lapó com arenitos subjacentes da Formação Alto Garças pode ser assim concordante ou caracterizado pela presença de hiatos, o que caracteriza sua natureza diastêmica;

3. As fácies subglaciais cessam seu movimento ao final da glaciação com o recuo das geleiras, consequentemente a idade dos tilitos marca o início da deglaciação; 4.0 recuo das geleiras disponibiliza grande carga sedimentar, dando origem às fácies marinhas glacialmente influenciadas Dms e Fld, que sobrepõem os tilitos e fácies associadas; 5. As fácies subglaciais depositadas por geleiras se deslocando sobre o fundo de plataformas de mares rasos têm as mesmas características faciológicas de fácies subglaciais de geleiras essencialmente terrestres. Têm, entretanto, potencial de preservação muito maior, não só por se depositarem abaixo do

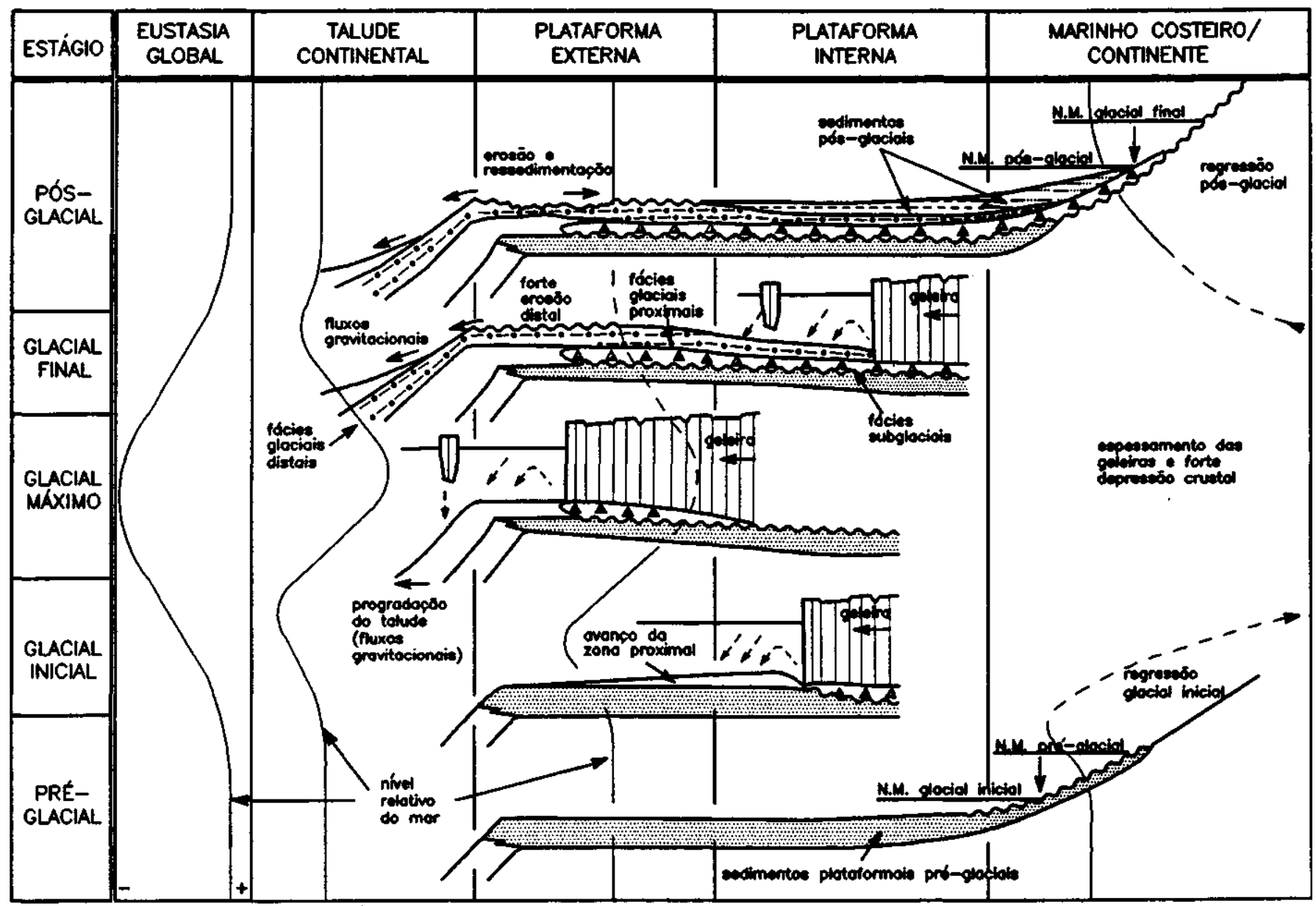

FACIES:

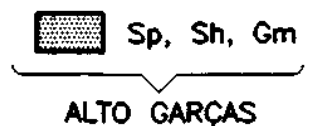

Dmm, Gm, St, sg D Drs, Sr, Fld

FORMAÇĀO:

ALTO GARCAS IAPÓ

F, H

VILA MARIA

Figura 9 - Modelo (adaptado de Boulton 1990) para explicar a arquitetura estratigráfica glácio-marmha da sequência ordovício-siluriana da Bacia do Paraná

Figure 9 - Model (based on Boulton 1990) to explain the glaciomarine stratigraphic architecture of ordovician-Silurian sequence of the Paraná basm 
nível de base (nível do mar), mas também porque são recobertas por fácies marinhas transgressivas, no caso representadas pela Formação Vila Maria

A área de ocorrência da Formação lapó é muito ampla, de forma que se deve esperar variações faciológicas laterais, especialmente para oeste no sentido do paleomergulho deposicional. Este parece ser o caso da ocorrência na fazenda da Concremix em Cipolândia (norte de Aquidauana-MS; ponto 17 da figura 5), uma área ainda pouco estudada onde, abaixo da seção pelítica da Formação Vila Maria, ocorrem fácies de matriz arenosa com seixos caoticamente distribuídos, alguns facetados e estriados, interpretadas como depósitos glaciogênicos ressedimentados por fluxos gravitacionais.

Depósitos glaciogênicos não foram ainda encontrados na seção ordovício-siluriana da Bacia do Paraná no Paraguai. A ausência de depósitos glaciais no Paraguai pode ter sido consequência de não deposição devido à área se situar em condições muito distais ou de erosão com o rebound glácioisostático. Mas considerando os dados e interpretações apresentados neste trabalho, fica evidente que novas investigações são necessárias e que a seção paraguaia merece ser revisitada.

Agradecimentos Ao Dr. Almério Barros França e a um colega anónimo, relatores da RBG, pela revisão e sugestões apresentadas; aos desenhistas Oto Laurentino Rosa, António Cezário Porta Jr. e Sônia P. Radomski pelas ilustrações; à FAPESP (proc. 1995/0770-0) e ao CNPq (proc. 400798/93-0) pêlos auxílios à pesquisa.

\section{REFERENCIAS}

Assine, M. L. 1996. Aspectos da estratigrafia das sequências pré-carboniferas da Bacia do Paraná no Brasil. São Paulo, 207p. (Tese de Doutoramento, IGUSP)

Assine, M. L. \& Soares, P.C. 1989. Correlações nas sequências mesopaleozóicas da Bacia do Paraná. Acta Geológica Leopoldensia 12(29):39-48.

Assine, M. L. \& Soares, P. C. 1993. Glaciacão neo-ordoviciana na Bacia do Paraná. In: Simpósio de Cronoestratigrafia da Bacia do Paraná, 1, Rio Claro, 1993. B. Resumos... Rio Claro, p. 8-9.

Assine, M. L.; Soares, P. C.; Milani, E. J. 1994. Sequências tectono-sedimentares mesopaleozóicas da Bacia do Paraná, Sul do Brasil. Rev. Brás. Geoc., 24(2): 77-89.

Baldis, B. \& Blasco, G. 1975. Primeros trilobitas ashgillianos dei Ordovícico sudamericano. Congresso Argentino de Paleontologia e Bioestratigrafla, Tucumán. Actas... Tucumán, 1.1, p. 33-48.

Benedetto, J.L. 1990. Los géneros Cliftonia y Paromalomena (Brachiopoda) en el Ashgilliano tardio de Ia Sicrra de Villicum, Precordillera de San Juan, Argentina. Ameghiniana, 27(1-2): 151 -159.

Beurlen, K. 1959. Geologia da zona de Barra do Garças a Chavantina Estado do Mato Grosso. Rio de Janeiro, DNPM/DGM, 61 p. (Boletim 193).

Borghi, L. \& Moreira, M.I.C. 1996. Aspectos petrológicos dos diamictitos das formações lapó e Vila Maria (Bacia do Paraná). In: Congresso Brasileiro de Geologia, 39, Salvador, 1996. Anais... Salvador, v.l, p. 149-151.

Borghi, L. \& Sschubert, G. 1995. Nova ocorrência da formação lapó no Estado do Paraná. An. Acad. Brás. Ci., 67: 387.

Boulton, G.S. 1990. Sedimentary and sea levei changes during glacial cycles and their controi on glacimarine fácies architecture. In: Dowdeswell, J.A. \& Scourse, J.D. (eds.). Glacimarine Environinents: processes and sediments. Londres, Geological Society, p. 15-52 (Sp. Publication 53).

Brenchley, P.J.; Romano, M.; Young, T.P.; Storch, P. 1991. Hirnantian glaciomarine diamictites -evidence for the spread glaciation and its effect on Upper Ordovician faunas. In: Barnes, C.R. \& Williams, S.H. ed. Advances in Ordovician Geology. Geol. Surv. Can., p. 325-336 (Paper 90-9).

Caputo, M.V. \& Crowell, J.C. 1985. Migration of glacial centers across Gondwana during Paleozoic Era. Geol. Soe. Amer. Buli. 96:1020-1036.

Deynoux, M. 1985. Terrestrial or waterlain glacial diamictites? Three case studies from the Late Precambrian and Late Ordovician glacial drifts in West África. Palaeogeogr., Palaeoclimat., Palaeoecol. 51:97-141.

Eyles, N., Eyles, C.H., Miall, A.D. 1983. Lithofacies types and vertical profile models: an alternative approach to the description and environmental interpretation of glacial diamict and diamictite sequences. Sedimentology, 30: 393-410.

Faria, A. 1982. Formação Vila Maria - nova unidade litoestratigráfica siluriana da Bacia do Paraná. Rev. Ciênc. da Terra 3:12-15.

Faria, M.M.; Pereira, E.; Cesero, P. 1994. Possíveis evidências de uma mobilidade tectônica pré-Furnas na região do Arco de Ponta Grossa: Bacia do Paraná. In: CONGR. BRÁS. GEOL., 38, Camboriú, 1994. Anais... Camboriú, SBG, v.l, p. 100-101.

Grahn, Y. \& Caputo, M.V. 1992. Early Silurian glaciations in Brazil. Palaeogeogr.. Palaeoclimat., Palaeoecol., 99: 9-15.

Gray, J.; Colbath, G.K.; Faria, A.; Boucot, A.J.; Rohr, D.M. 1985. Silurian-age fossils from the Paleozoic Paraná Basin, Southern Brazil. Geology 13:521-525.

Laubacher, G.; Boucot, A.J.; Gray, J. 1982. Additions to Silurian stratigraphy, lithofacies, biogeography e paleontology of Bolívia and Southern Peru. J. Paleont. 56(5): 1138-1170.
Levy, R. \& Nullo, F. 1974. La fauna ordovícica (Ashgilliano) de Villicum, San Juan, Argentina. Ameghiniana, 9:173-194.

Maack, R. 1947. Breves notícias sobre a geologia dos estados do Paraná e Santa Catarina. Curitiba, Arquivos de Biologia e Tecnologia (IBPT), 11:63-154.

Maack, R. 1950-51. Vestígios pré-devonianos de glaciação e a sequência de camadas devonianas no Estado do Paraná. Curitiba, Arquivos de Biologia e Tecnologia (IBPT), V-VI: 197-230.

Monaldi, C.R. \& Boso, M.A. 1987. Dalmanitina (D.) subandina n.sp. (trilobita) en Ia Formación Zapla dei Norte Argentino. Congresso Latinoamericano de Paleontologia, 4. Actas... t.l, p. 149-158.

Peralta, S.H. \& Baldis, B. A.J. 1992. Diamictitas dei Ordovícico tardio sudamericano: correlaciones regionales y su relacion com un evento glacial gondwanico. In: Reunion Argentina de Sedimentologia, 4. Actas... v.3, p.169-176.

Peralta, S.H. \& Cárter, C.H. 1990. La glaciacion gondwanica dei Ordovícico tardio: evidências en fangolitas guijarrosas de Ia Precordillera de San Juan, Argentina. In: Congresso Geológico Argentino, 11. San Juan, 1990. Actas... San Juan, AGA. v. II, p. 181-185.

Pereira, E. 1992. Análise estratigráfica do Paleozóico médio da Sub-Bacia do Alto Garcas, no sudoeste de Goiás. Bacia do Paraná, Brasil. Rio de Janeiro, IG/UFRJ (Dissertação de Mestrado), 172p.

Petri, S. \& Fulfaro, V. J. 1967. Considerações geológicas sobre a região de Itapeva, SP. Boi. Soe. Brás. Geol., 16:25-41.

Rocha-Campos, A. C. 1981. lapó Formation. In: Hambrey, M.J. \& Harland, W.B. (eds.) Earth's Pre-Pleistocene Glacial Record. Cambridge, Cambridge University Press, p. 908-909.

Sanchez, T.M.; Benedetto, J.L.; Brussa, E. 1991. Late Ordovician stratigraphy, paleoecology, and sea levei changes in the Argentine Precordillera. In: Barnes, C.R. \& Williams, S.H. ed. Advances in Ordovician Geology. Geol. Surv. Can., p. 245-258 (Paper 90-9).

Schlagintweit, O. 1943. La posición estratigráfica dei yacimiento ferrifero de Zapla y Ia difusión dei horizonte glacial de Zapla en Ia Argentina y en Bolívia. Buentos Aires, Revista Minem, 13(4): 115-127.

Suarez-Soruco, R. 1992. El Paleozóico Inferior de Bolívia y Peru. In: Gutierrez-Marco, J.C.; Saavedra, J.; Rábano, I. (eds.) Paleozóico Inferior de Ibero-América. Espanha, Universidade de Extremadura, p. 225-239.

Vaslet, D. 1990. Upper Ordovician glacial deposits in Saudi Arábia. Episodes 13(3): 147-161.

Vieira, A. J. 1973. Geologia do centro e nordeste do Paraná e centro-sul de São Paulo. In: Congresso Brasileiro de Geologia, 27, Aracaju, 1973. Anais... Aracaju, SBG, v.3, p.259-277.

Vieira, A.J. \& Maingue, E. 1972. Geologia de semi-detalhe do centro e nordeste do Paraná e centro-sul de São Paulo. Ponta Grossa, Petrobrás/DESUL, 49p. (Relatório 425).

Visser, J.N.J. 1989. The distinction between ancient mountain and shelf glaciations. In: Intern. Geol. Congr., 28, Washington D.C., 1989. Abstracts... v.3, p.303-304.

Visser, J. N. J. 1992. The late Ordovician Pakhuis Glaciation in the Cape Supergroup, South África. In: Congresso Brasileiro de Geologia, 37 São Paulo, 1992. Boi. Resumos Expandidos... São Paulo, SBG, v. 1, p. 525-527.

Manuscrito A-944 Recebido em 21 de outubro de 1997 Revisão dos autores em 30 de janeiro de 1998 Revisão aceita em 01 de fevereiro de 1998 